\title{
Parameter selection in non-traditional machining processes using a data mining approach
}

\author{
Somen Dey and Shankar Chakraborty*
}

Department of Production Engineering, Jadavpur University Kolkata - 700 032, India

\begin{tabular}{l}
\hline C H R O N I C L E \\
\hline Article history: \\
Received July 10, 2014 \\
Accepted December 17, 2014 \\
Available online \\
December 18 2014 \\
\hline Keywords: \\
Non-traditional machining \\
process \\
Data mining \\
CART algorithm \\
Process parameter
\end{tabular}

\section{Introduction}

With the development of technology, more and more challenging problems are now being faced by the scientists and engineers in the field of manufacturing. Non-traditional machining (NTM) processes are now gaining importance because of their capability to machine new and advanced materials, like ceramics, composites, fiber reinforced materials, tungsten carbides, stainless steels, high speed steels, carbides, titanium-based alloys etc. for generating small cavities, slots, slits, blind or through holes at micro- and even at nano-level. These newer materials are characterized by extreme hardness and brittleness and hence, cannot be efficiently machined by the conventional machining methods. Conventional machining processes remove material from the workpiece by chip formation, abrasion or micro-chipping. There are situations, however, where these processes are not satisfactory, economical or even possible as hardness and strength of the work material, and the complex shape geometry hinder their applications. Sometimes, the workpiece is too flexible, slender or delicate to withstand the cutting or grinding forces. The requirements of high surface finish, dimensional tolerance, minimum heat affected zone and low residual stress generation also do not favor the applications of the conventional machining processes. These together with the demand for stringent technological and functional

\footnotetext{
* Corresponding author

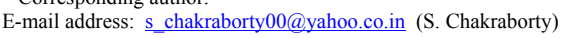

(C) 2015 Growing Science Ltd. All rights reserved.

doi: $10.5267 /$ j.dsl.2014.12.001
}

\author{
(1)
}


requirements of the machined components in the micro- or nano-range have stimulated the wide spread applications of NTM processes in the present day manufacturing environment. Today, NTM processes with varying capabilities and specifications are available to cater a wide range of applications. Apart from mechanical energy, these processes utilize other sources of energy, like electrical energy, chemical energy, thermal energy or combination of those energies to remove material from the workpiece, sometimes even not touching its surface (Debroy \& Chakraborty, 2013). The performance and success of these NTM processes are greatly influenced by their input parameters and in order to explore the fullest capability of these processes, it is often desirable to identify the most prevailing control parameters of these processes along with their optimal settings. In this paper, a data mining approach using classification and regression tree (CART) algorithm is adopted to investigate the effects of various control parameters of three NTM processes, i.e. electro discharge milling process, wire electrical discharge machining process and laser beam machining process. For each of these three NTM processes, the most predominant control parameter is identified and its contribution to various process responses is determined which is further validated using the analysis of variance (ANOVA) results.

\section{CART algorithm}

The CART algorithm is a machine learning method for constructing prediction models from raw data. It is based on recursive partitioning of the data space and fitting a simple prediction model within each partition. This partitioning is represented graphically as a decision tree. These classification trees are designed for dependent variables that take a finite number of unordered values, with the prediction error measured in terms of misclassification cost. On the other hand, regression trees for dependent variables take continuous or ordered discrete values, with prediction error typically measured by the squared difference between the observed and predicted values. CART is basically a binary decision tree algorithm that recursively partitions data into two subsets so that cases within each subset are more homogeneous. It allows consideration of misclassification costs, prior distributions and cost complexity pruning. The CART algorithm also allows automatic selection of the 'right-sized' tree that has the optimal prediction accuracy. The procedures for the 'right-sized' tree selection are not foolproof, but at least, they take the subjective judgment out of the process of selecting the 'right-sized' tree and thus, avoid 'over fitting' and 'under fitting' of the data (Breiman et al.,1984; Maimon \& Rokach, 2005).

The CART algorithm is based on the following procedural steps:

a) The basic idea is to choose a split at each node so that data in each subset (child node) is purer than the data in parent node. It measures the impurity of the data in the nodes of a split with an impurity measure $i(t)$.

b) If the split $s$ at node $t$ sends a proportion $P_{L}$ of data to its left child node $t_{L}$ and a corresponding proportion $P_{R}$ of data to its right node $t_{R}$, the decrease in the impurity of split $s$ at node $t$ is accordingly calculated.

c) A CART tree is grown, starting from its root node (the entire data set) by searching for a split $S^{*}$ among the set of all possible candidates $S$ which give the largest decrease in impurity.

d) The above split searching process is repeated for each child node.

e) The tree growing process is stopped when all the stopping criteria are met.

For the purpose of developing the corresponding decision tree, the set of experimental dataset is subjected to CART analysis (available in STATISTICA software) using the following specifications: Split selection method - CART style exhaustive search for univariate splits, Misclassification cost equal, Measure of goodness of fit for a split - Gini measure (at each node, the split that generates the greatest improvement in the prediction accuracy is selected), Prior probabilities - Estimated, Stopping rule - Prune on misclassification error (pruning is performed to produce a sequence of optimally pruned and nested trees, which facilitate selection of the 'right-sized' tree), Stopping parameters - Minimum $n$ $=5$ ('Minimum $n$ ' rule implies that splitting is allowed to continue until all the terminal nodes are pure or contain no more than ' $n$ ' cases), Standard error rule $=1.0$ ('d standard error' rule implies choosing 
the smallest-sized tree from all trees whose cross validation (CV) cost does not exceed the minimum $\mathrm{CV}$ cost plus d times the standard error of the minimum CV cost as the 'right-sized' tree), and Sampling options: Seed for random number generator $=12$ and $\mathrm{V}$ fold $\mathrm{CV}$ value $=3$.

\section{Illustrative examples}

In order to demonstrate the applicability of CART algorithm in properly identifying the most predominant control parameters in NTM processes, the following three examples are cited.

\subsection{Example 1: Micro electro discharge milling process}

Electro discharge milling is a prominent NTM process used for machining hard and difficult-tomachine conductive materials. It is a controlled metal removal process used to remove material by means of electric spark erosion. In this process, an electric spark is used as the cutting tool to cut (erode) the workpiece to generate the desired shape on the work material. The metal removal process takes place while applying a pulsating electrical charge of high frequency current through the electrode to the workpiece. This removes (erodes) very tiny pieces of metal from the work material at a controlled rate. The metal removal mechanism of this process is excellently detailed out in (Ho \& Newman, 2003; Liu et al., 2008; Rajurkar et al., 2013; Skrabalak et al., 2013). Mehfuz and Ali (2009) studied the effects of three micro electro discharge milling process parameters, i.e. feed rate, capacitance and voltage on four responses, i.e. average surface roughness (Ra), maximum peak-to-valley roughness height (Ry), tool wear ratio (TWR) and material removal rate (MRR). The experimental plan, as given in Table 1, was based on three-level factorial statistical model in order to investigate the individual as well as interaction effects of the three process parameters on the considered responses. A data mining approach based on CART algorithm is now employed which applies rule induction to analyze this experimental dataset. It enables rules to be automatically generated from the experimental data. Decision trees are subsequently developed to analyze the data and discover patterns in it (Kuriakose et al., 2003). Fig. 1 shows the graphical representation of a decision tree, developed using CART algorithm. In this figure, Class 1 refers to Ra values $\leq 0.23 \mu \mathrm{m}$ and Class 2 denotes Ra values $>0.23 \mu \mathrm{m}$, where $0.23 \mu \mathrm{m}$ is the average Ra value obtained from the experimental data. It is noticed here that capacitance is the only significant factor influencing Ra. In this decision tree, there are only two terminal nodes, which are the points on the tree beyond which no further decisions can be made. The tree starts with a top decision node, sometimes called the root node (labeled as node 1).

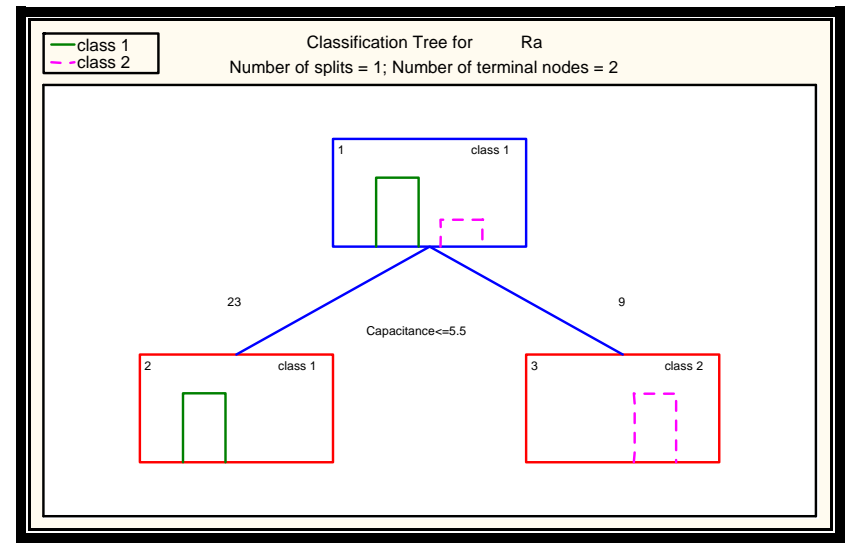

Fig. 1. Classification tree for Ra (two classes)

Initially, all the 32 data points are assigned to this root node and tentatively classified as Class 1 . Class 1 is chosen as the initial classification node because there are slightly more Class 1 Ra values than Class 2, as indicated by the histogram plotted inside the root node. The root node is then split forming 
two new nodes. It indicates that the data points with capacitance values $\leq 5.5 \mathrm{nF}$ are sent to node 2 (terminal node) and classified as Class 1, and the remaining data points with capacitance values $>5.5$ $\mathrm{nF}$ are assigned to node 3 (terminal node) and classified as Class 2. Thus, 23 cases are classified as Class 1 and the remaining nine as Class 2 . Hence, it is seen that all the 32 data sets are successfully classified by CART algorithm having no wrong prediction (misclassification).

Table 1

Experimental results of micro electro discharge milling process (Mehfuz \& Ali, 2009)

\begin{tabular}{|c|c|c|c|c|c|c|c|}
\hline \multirow[b]{2}{*}{ Exp. No. } & \multicolumn{3}{|c|}{ Process parameter } & \multicolumn{4}{|c|}{ Response } \\
\hline & $\begin{array}{c}\text { Feed rate } \\
\left(\mu \mathrm{m} \mathrm{s}^{-1}\right)\end{array}$ & $\begin{array}{c}\text { Capacitance } \\
(\mathrm{nF})\end{array}$ & $\begin{array}{l}\text { Voltage } \\
(\mathrm{V})\end{array}$ & $\begin{array}{c}\mathrm{Ra} \\
(\mu \mathrm{m})\end{array}$ & $\begin{array}{c}\text { Ry } \\
(\mu \mathrm{m})\end{array}$ & TWR & $\begin{array}{c}\mathrm{MRR}(\mathrm{mg} \\
\left.\mathrm{min}^{-1}\right)\end{array}$ \\
\hline 1 & 2.00 & 0.10 & 80.00 & 0.04 & 0.31 & 0.121 & 0.02 \\
\hline 2 & 4.00 & 0.10 & 80.00 & 0.04 & 0.35 & 0.044 & 0.07 \\
\hline 3 & 6.00 & 0.10 & 80.00 & 0.04 & 0.36 & 0.133 & 0.09 \\
\hline 4 & 2.00 & 1.00 & 80.00 & 0.10 & 0.78 & 0.154 & 0.04 \\
\hline 5 & 4.00 & 1.00 & 80.00 & 0.12 & 0.91 & 0.066 & 0.09 \\
\hline 6 & 6.00 & 1.00 & 80.00 & 0.10 & 0.89 & 0.165 & 0.09 \\
\hline 7 & 2.00 & 10.00 & 80.00 & 0.44 & 3.23 & 0.182 & 0.06 \\
\hline 8 & 4.00 & 10.00 & 80.00 & 0.44 & 3.21 & 0.089 & 0.10 \\
\hline 9 & 6.00 & 10.00 & 80.00 & 0.48 & 3.53 & 0.220 & 0.11 \\
\hline 10 & 2.00 & 0.10 & 100.00 & 0.05 & 0.49 & 0.165 & 0.03 \\
\hline 11 & 4.00 & 0.10 & 100.00 & 0.05 & 0.40 & 0.049 & 0.09 \\
\hline 12 & 6.00 & 0.10 & 100.00 & 0.06 & 0.54 & 0.157 & 0.09 \\
\hline 13 & 2.00 & 1.00 & 100.00 & 0.19 & 1.28 & 0.194 & 0.06 \\
\hline 14 & 4.00 & 1.00 & 100.00 & 0.17 & 1.20 & 0.065 & 0.16 \\
\hline 15 & 6.00 & 1.00 & 100.00 & 0.18 & 1.38 & 0.186 & 0.14 \\
\hline 16 & 2.00 & 10.00 & 100.00 & 0.53 & 3.99 & 0.239 & 0.10 \\
\hline 17 & 4.00 & 10.00 & 100.00 & 0.54 & 4.08 & 0.098 & 0.35 \\
\hline 18 & 6.00 & 10.00 & 100.00 & 0.53 & 4.05 & 0.216 & 0.13 \\
\hline 19 & 2.00 & 0.10 & 120.00 & 0.05 & 0.44 & 0.198 & 0.06 \\
\hline 20 & 4.00 & 0.10 & 120.00 & 0.07 & 0.52 & 0.065 & 0.15 \\
\hline 21 & 6.00 & 0.10 & 120.00 & 0.08 & 1.23 & 0.166 & 0.10 \\
\hline 22 & 2.00 & 1.00 & 120.00 & 0.19 & 1.81 & 0.227 & 0.07 \\
\hline 23 & 4.00 & 1.00 & 120.00 & 0.17 & 1.22 & 0.086 & 0.36 \\
\hline 24 & 6.00 & 1.00 & 120.00 & 0.18 & 1.37 & 0.198 & 0.14 \\
\hline 25 & 2.00 & 10.00 & 120.00 & 0.56 & 3.11 & 0.261 & 0.16 \\
\hline 26 & 4.00 & 10.00 & 120.00 & 0.62 & 3.79 & 0.128 & 0.41 \\
\hline 27 & 6.00 & 10.00 & 120.00 & 0.54 & 3.77 & 0.247 & 0.15 \\
\hline 28 & 4.00 & 1.00 & 100.00 & 0.22 & 1.30 & 0.058 & 0.10 \\
\hline 29 & 4.00 & 1.00 & 100.00 & 0.22 & 1.53 & 0.072 & 0.49 \\
\hline 30 & 4.00 & 1.00 & 100.00 & 0.15 & 1.06 & 0.067 & 0.24 \\
\hline 31 & 4.00 & 1.00 & 100.00 & 0.19 & 1.47 & 0.062 & 0.13 \\
\hline 32 & 4.00 & 1.00 & 100.00 & 0.16 & 1.28 & 0.075 & 0.20 \\
\hline
\end{tabular}

Another decision tree of Fig. 2 is developed where the Ra values are classified into three classes, i.e. Class $1(\mathrm{Ra} \leq 0.04 \mu \mathrm{m})$, Class $2(0.04 \mu \mathrm{m}<\mathrm{Ra} \leq 0.18 \mu \mathrm{m})$ and Class $3(\mathrm{Ra}>0.18 \mu \mathrm{m})$. This classification tree has 5 splits and 6 terminal nodes. All the 32 data sets are first assigned to the root node and are classified as Class 2, as there are slightly more Class 2 Ra values than the other classes in the original data set. The root node is then split into two new nodes. The data sets with capacitance values $\leq 5.5 \mathrm{nF}$ are sent to node 2 and subsequently classified as Class 2, and the remaining data sets with capacitance values $>5.5 \mathrm{nF}$ are assigned to node 3 and classified as Class 3 . Similarly, node 2 is subsequently split where six data sets with voltage values $\leq 90 \mathrm{~V}$ are sent to node 4 and classified as 
Class 1 , and the remaining 17 data sets with voltage values $>90 \mathrm{~V}$ are sent to node 5 and classified as Class 2. This procedure of splitting of nodes continues further until the terminal nodes are reached and the nodes can no further be split. In node 11 , for capacitance $\leq 5.5 \mathrm{nF}$, voltage $>90 \mathrm{~V}$, capacitance $>$ $0.55 \mathrm{nF}$ and feed rate $>3 \mu \mathrm{m} \mathrm{s}^{-1}$, three cases are misclassified with a misclassification rate of $9.38 \%$. It is also observed from the decision tree that capacitance is used maximum number of times for performing the split operations and it is thus the most predominant process parameter in controlling $\mathrm{Ra}$ values. Fig. 3 shows the predictor variable importance ranking for Ra values and it is quite interesting to observe from this figure that for Ra values capacitance plays the most significant role. The ANOVA results of Table 2 for Ra values also assure that capacitance has the maximum contribution in attaining the desired Ra values in this machining process.

Table 2

ANOVA results for Ra values

\begin{tabular}{cccccc}
\hline Effect & DF & SS & MS & F & \% contribution \\
\hline Feed rate & 2 & 0.00196 & 0.00098 & 1.34 & $0.04 \%$ \\
Capacitance & 2 & 1.09206 & 0.54603 & 747.58 & $95.65 \%$ \\
Voltage & 2 & 0.02792 & 0.01396 & 19.11 & $2.32 \%$ \\
Error & 25 & 0.01826 & 0.00073 & & $1.98 \%$ \\
\hline Total & 31 & 1.14019 & & & \\
\hline
\end{tabular}

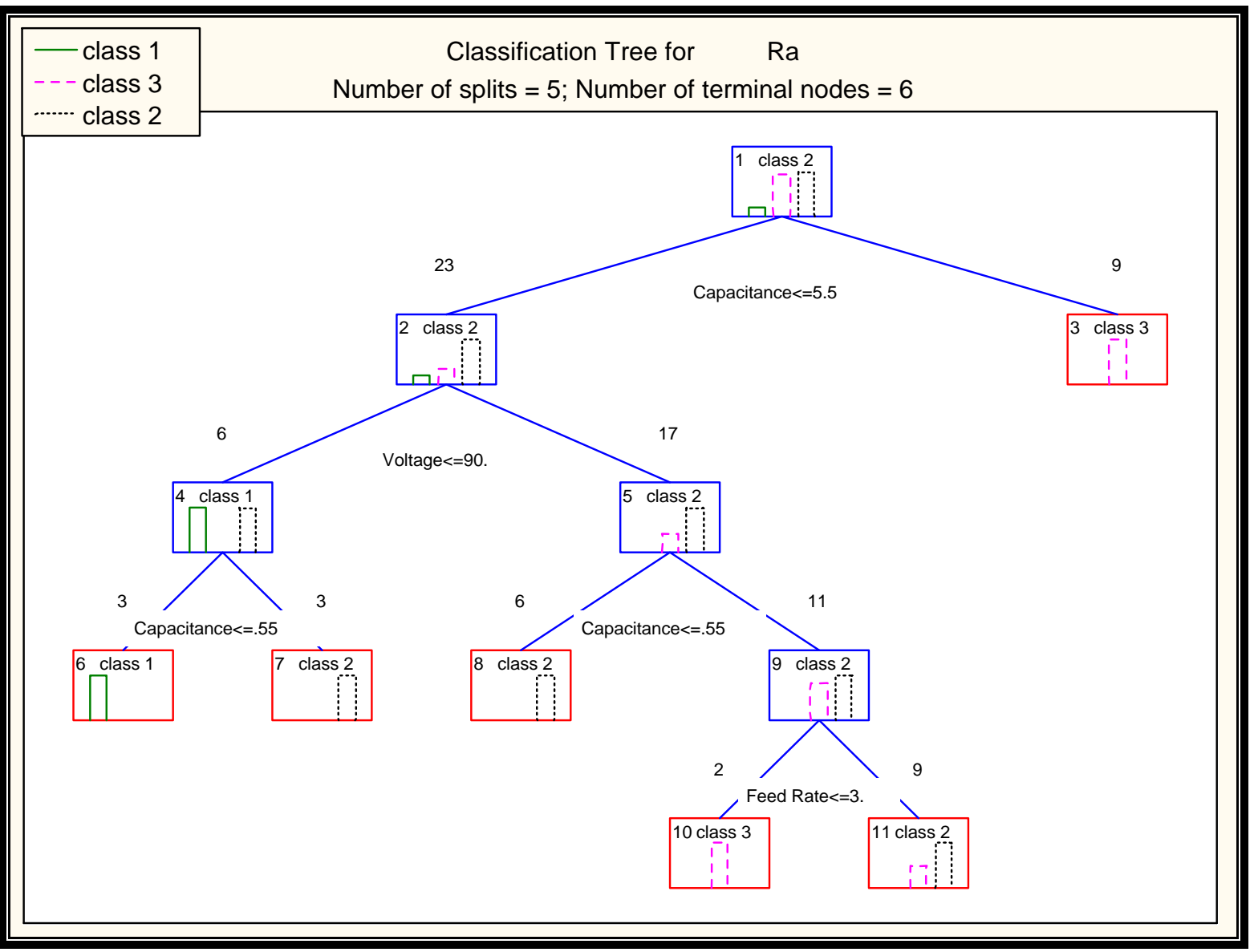

Fig. 2. Classification tree for Ra (three classes)

Similarly, for Ry values, two classes are first defined, i.e. Class 1 (for Ry $\leq 1.72 \mu \mathrm{m}$ ) and Class 2 (for Ry $>1.72 \mu \mathrm{m}$ ), where $1.72 \mu \mathrm{m}$ is the average Ry value as calculated from the experimental data. From the developed decision tree, it is observed that capacitance is the most significant input parameter and 23 data sets are grouped as Class 1 with capacitance values $\leq 5.5 \mathrm{nF}$, having only one misclassified Ry 
value (misclassification rate 3.125\%). In Figure 4, the decision tree where Ry values are classified into three classes, i.e. Class 1: Ry $\leq 1.26 \mu \mathrm{m}$, Class 2: $1.26 \mu \mathrm{m}<\mathrm{Ry} \leq 2.52 \mu \mathrm{m}$ and Class 3: $2.52 \mu \mathrm{m}<$ Ry $\mu \mathrm{m}$ is developed using CART algorithm. It can be seen from the split results that all the process parameters, i.e. capacitance, voltage and feed rate are employed for performing the split operations. The misclassification rate in the developed tree is $6.25 \%$. It is observed from the corresponding ANOVA results of Table 3 that capacitance has again the highest percentage contribution in influencing Ry values.

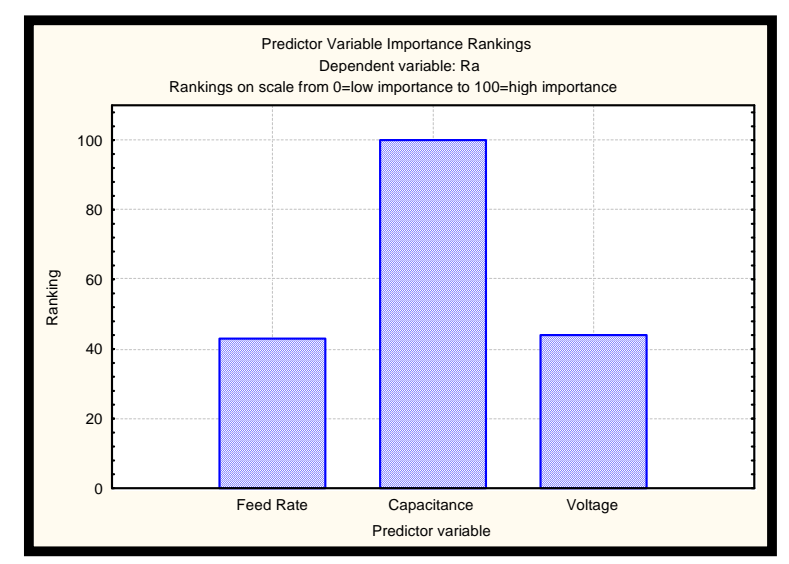

Fig. 3. Predictor variable importance ranking for $\mathrm{Ra}$

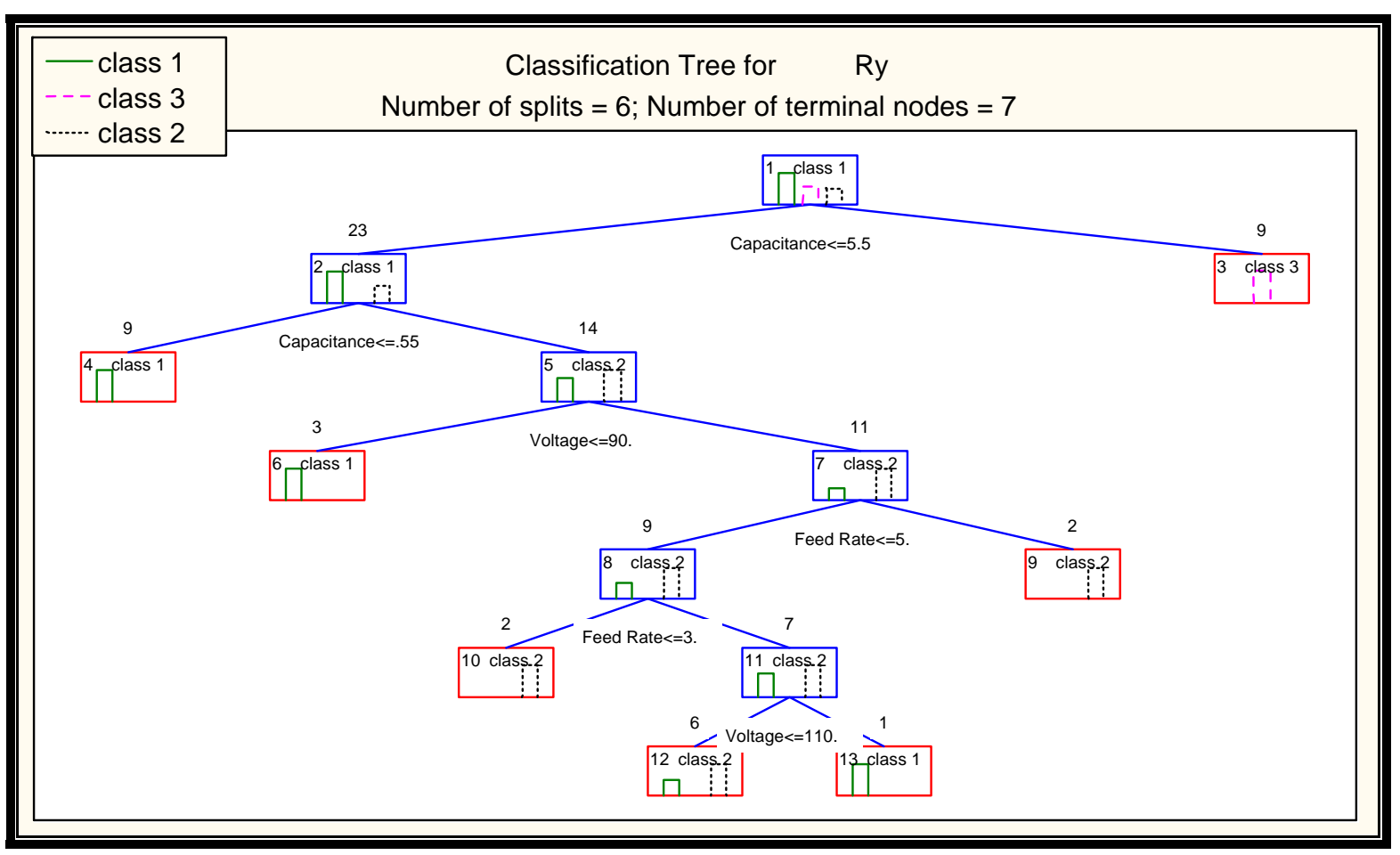

Table 3

Fig. 4. Classification tree for prediction of Ry (three classes)

ANOVA results for Ry values

\begin{tabular}{cccccc}
\hline Effects & DF & SS & MS & F & \% contribution \\
\hline Feed rate & 2 & 0.5195 & 0.25975 & 4.35 & $0.77 \%$ \\
Capacitance & 2 & 48.9842 & 24.4921 & 410.14 & $93.75 \%$ \\
Voltage & 2 & 1.1237 & 0.56185 & 9.41 & $1.93 \%$ \\
Error & 25 & 1.4929 & 0.05972 & & $3.55 \%$ \\
\hline Total & 31 & 52.1202 & & & \\
\hline
\end{tabular}


From the developed decision tree for two class classification of TWR values (Class 1: TWR $\leq 0.166$ and Class 2: $0.166<$ TWR), it is observed that feed rate has the significant contribution in influencing TWR values. Figure 5 shows the decision tree where TWR values are classified into three classes (Class 1: TWR $\leq 0.072$, Class 2: $0.072<$ TWR $\leq 0.144$ and Class 3: $0.144<$ TWR). All the three process parameters play major roles in splitting of TWR values and subsequent development of the decision tree. The misclassification rate is predicted to be only $3.125 \%$. The ANOVA results of Table 4 also confirm that feed rate has the maximum contribution, affecting TWR in comparison to the other two process parameters.

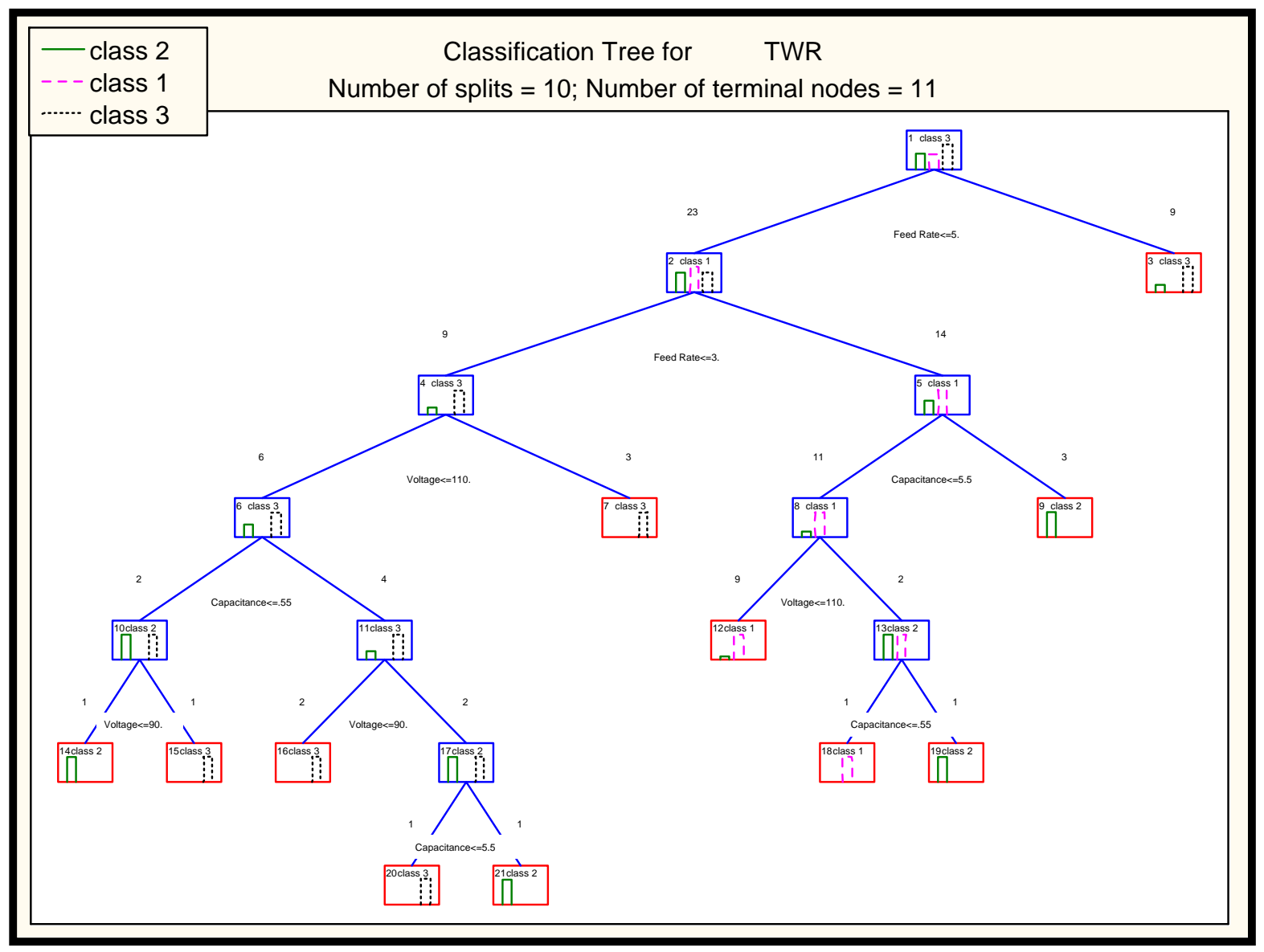

Fig. 5. Classification tree for prediction of TWR (three classes)

Table 4

ANOVA results for TWR

\begin{tabular}{cccccc}
\hline Effect & DF & SS & MS & F & \% contribution \\
\hline Feed rate & 2 & 0.108616 & 0.054308 & 360.23 & $77.04 \%$ \\
Capacitance & 2 & 0.019198 & 0.009599 & 63.67 & $13.44 \%$ \\
Voltage & 2 & 0.009009 & 0.0045045 & 29.88 & $6.19 \%$ \\
Error & 25 & 0.003769 & 0.0001507 & & $3.32 \%$ \\
\hline Total & 31 & 0.140592 & & & \\
\hline
\end{tabular}

The decision tree, developed in Fig. 6, where MRR values are classified into three classes, i.e. Class 1: $\mathrm{MRR} \leq 0.16 \mathrm{mg} / \mathrm{min}$, Class 2: $0.16 \mathrm{mg} / \mathrm{min}<\mathrm{MRR} \leq 0.32 \mathrm{mg} / \mathrm{min}$ and Class $3: 0.32<\mathrm{MRR} \mathrm{mg} / \mathrm{min}$, shows that all the three process parameters are equally responsible in the splitting operation. 
Table 5

ANOVA results for MRR

\begin{tabular}{cccccc}
\hline Effect & DF & SS & MS & F & \% contribution \\
\hline Feed rate & 2 & 0.122065 & 0.061033 & 8.77 & $27.90 \%$ \\
Capacitance & 2 & 0.042985 & 0.021493 & 3.09 & $7.50 \%$ \\
Voltage & 2 & 0.048683 & 0.024342 & 3.50 & $8.97 \%$ \\
Error & 25 & 0.173954 & 0.006958 & & $55.64 \%$ \\
\hline Total & 31 & 0.387687 & & & \\
\hline
\end{tabular}

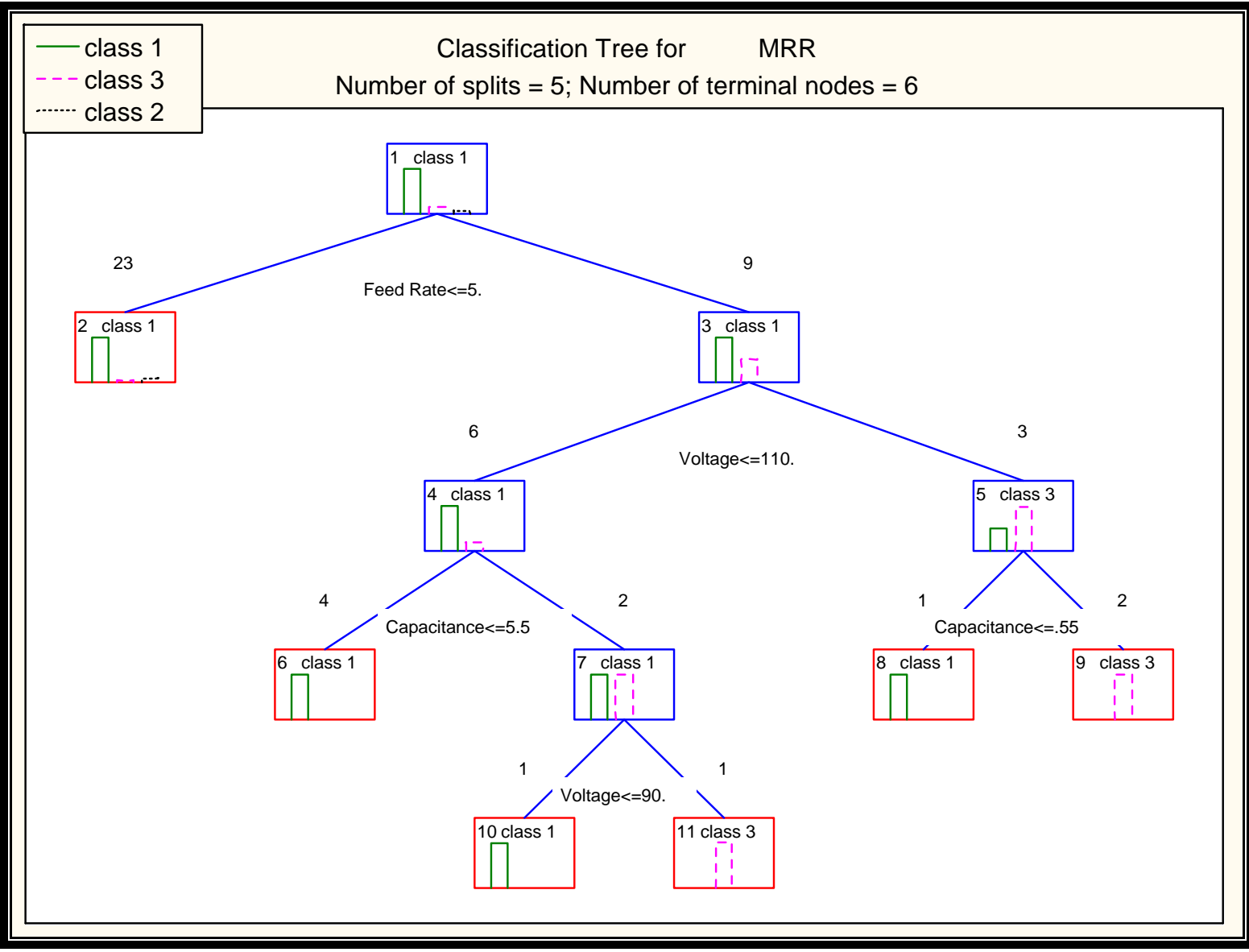

Fig. 6. Classification tree for prediction of MRR (three classes)

From the ANOVA results of Table 5, the percentage contributions of the three process parameters are estimated and it is observed that feed rate has the highest contribution in influencing MRR values. As the percentage contribution of the error term exceeds $50 \%$, there exists a good opportunity for further experimentation for having more insights in identifying the role of the three process parameters in controlling MRR values.

From the developed decision trees and ANOVA results, it is found that capacitance plays a major role in controlling the surface roughness parameters ( $R a$ and Ry), while for TWR and MRR, feed rate is the most dominant input parameter in this micro electro discharge milling process. The effects of these process parameters on the responses almost match with the observations of Mehfuz and Ali (2009).

\subsection{Example 2: Wire electrical discharge machining process}

Wire electrical discharge machining (WEDM) is a specialized thermal machining process capable of accurately machining product components with varying hardness or complexities. The practical 
technology of WEDM process is based on the conventional EDM process in which the electrode is a continuously moving electrically conductive wire (made of thin copper, brass or tungsten of diameter $0.05-0.3 \mathrm{~mm}$ ). The movement of this wire is numerically controlled to achieve the desired threedimensional shape on the work material. The wire is kept in tension using a mechanical device reducing the tendency of producing inaccurate shapes. The mechanism of material removal in WEDM process involves a complex erosion effect by rapid, repetitive and discrete spark discharges between the wire tool and the job immersed in a liquid dielectric (kerosene/deionized water) medium. These electrical discharges melt and vaporize minute amounts of work material, which are ejected and flushed away by the dielectric, leaving small craters on the work material. The detailed working principle of WEDM process is available in (Scott et al., 1991; Spedding \& Wang, 1997a , 1997b; Ho et al., 2004).

Sarkar et al. (2005) conducted 18 experiments to show the effects of six WEDM process parameters on three responses, i.e. machining speed $(\mathrm{mm} / \mathrm{min})$, average $\mathrm{Ra}$ (in $\mu \mathrm{m})$ and wire offset (in $\mathrm{mm})$. Each of the process parameters was set at three different levels, i.e. pulse-on time $\left(\mathrm{T}_{\mathrm{on}}\right)(0.8 \mu \mathrm{s}, 1 \mu \mathrm{s}, 1.6 \mu \mathrm{s})$, pulse-off time ( $\left.\mathrm{T}_{\text {off }}\right)(14 \mu \mathrm{s}, 20 \mu \mathrm{s}, 30 \mu \mathrm{s})$, peak current $\left(\mathrm{I}_{\mathrm{p}}\right)(120 \mathrm{~A}, 170 \mathrm{~A}, 200 \mathrm{~A})$, wire tension (WT) $(900 \mathrm{~g}, 1140 \mathrm{~g}, 1380 \mathrm{~g})$, servo reference voltage (SV) $(2 \mathrm{~V}, 6 \mathrm{~V}, 200 \mathrm{~V})$ and dielectric flow rate (discharge pressure) (FR) $\left(7 \mathrm{~kg} / \mathrm{cm}^{2}, 8.5 \mathrm{~kg} / \mathrm{cm}^{2}, 10 \mathrm{~kg} / \mathrm{cm}^{2}\right)$. Using the experimental data of this WEDM process, a data mining approach is adopted here to identify the most influencing parameters for achieving enhanced machining response values. The data mining approach based on CART algorithm is applied to all the three responses using two and three class classifications of the data set. Fig. 7 exhibits the decision tree for machining speed for two classes, i.e. Class 1 for machining speeds $\leq 1.88 \mathrm{~mm} / \mathrm{min}$ and Class 2 for machining speeds $>1.88 \mathrm{~mm} / \mathrm{min}(1.88 \mathrm{~mm} / \mathrm{min}$ is the average machining speed $)$. It is observed from the developed decision tree that pulse-on time maximally influences the machining speed response. Similarly, the related decision tree for three class classification for machining speed (Class 1: $0.98 \mathrm{~mm} / \mathrm{min} \leq$ machining speed $<1.54 \mathrm{~mm} / \mathrm{min}$, Class $2: 1.54 \mathrm{~mm} / \mathrm{min} \leq$ machining speed $<2.1 \mathrm{~mm} / \mathrm{min}$ and Class 3: $2.1 \mathrm{~mm} / \mathrm{min} \leq$ machining speed) is shown in Figure 8. From the results of CART algorhim-based analysis, it is can be concluded that although the process parameters $\mathrm{T}_{\text {on, }}, \mathrm{T}_{\text {off, }}$, $\mathrm{I}_{\mathrm{p}}$ and SV are mainly responsible for attaining the desired machining speed in WEDM process, Ton has the maximum contribution in influencing this response, followed by $T_{\text {off. The }}$ The observations are also validated using the ANOVA results of Table 6.

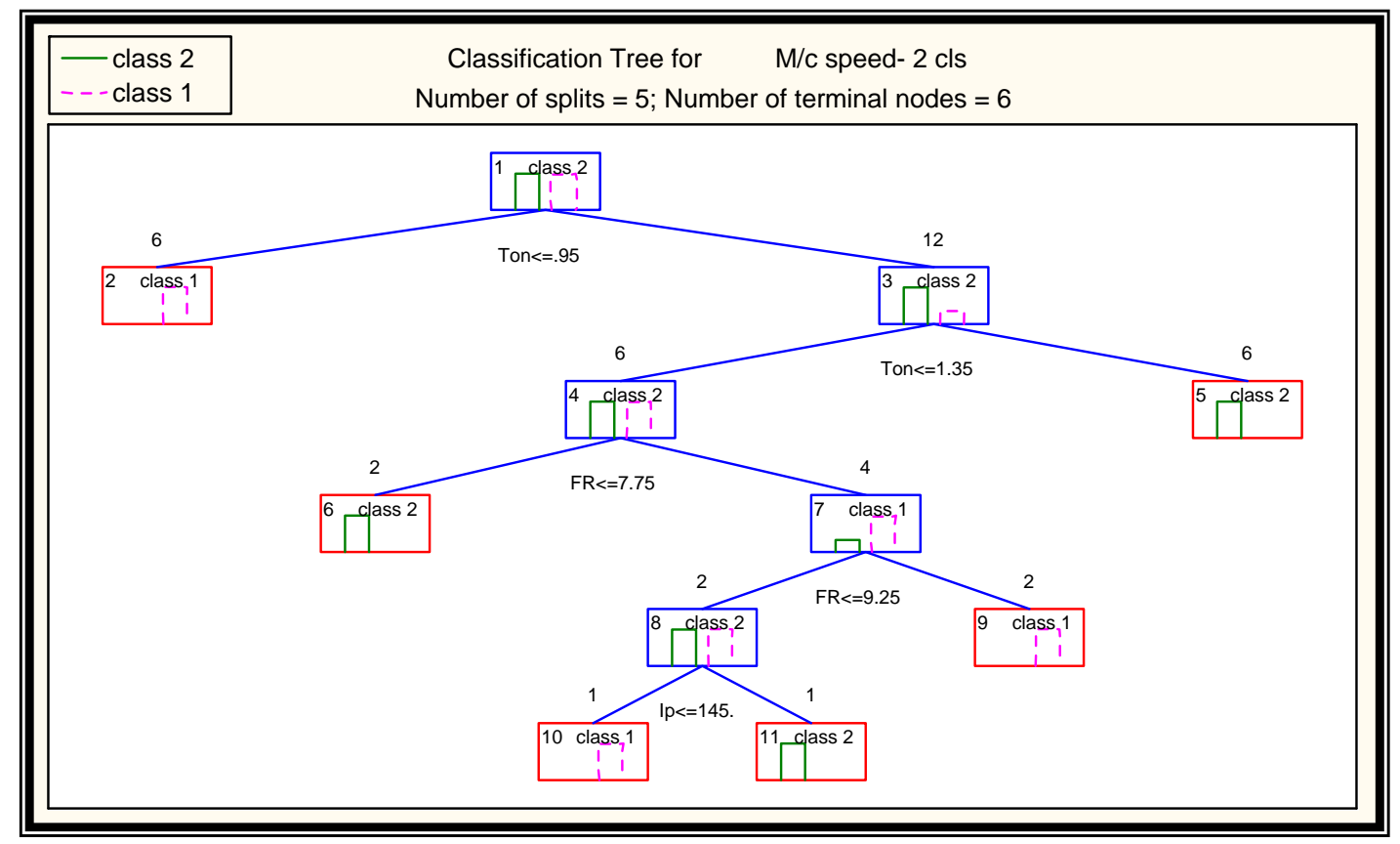

Fig. 7. Decision tree for machining speed (two classes) 
From the developed decision trees for Ra for two class (Class 1: Ra $\leq 2.68 \mu \mathrm{m}$ and Class 2: $\mathrm{Ra}>$ $2.68 \mu \mathrm{m})$ and three class $(0.23 \mu \mathrm{m} \leq \mathrm{Ra}<2.54 \mu \mathrm{m}$, Class $2: 2.54 \mu \mathrm{m} \leq \mathrm{Ra}<2.78 \mu \mathrm{m}$ and Class 3: 2.78 $\mu \mathrm{m} \leq \mathrm{Ra}$ ) classifications, it is found that pulse-on time has the maximum contribution as the input parameter in controlling Ra values.

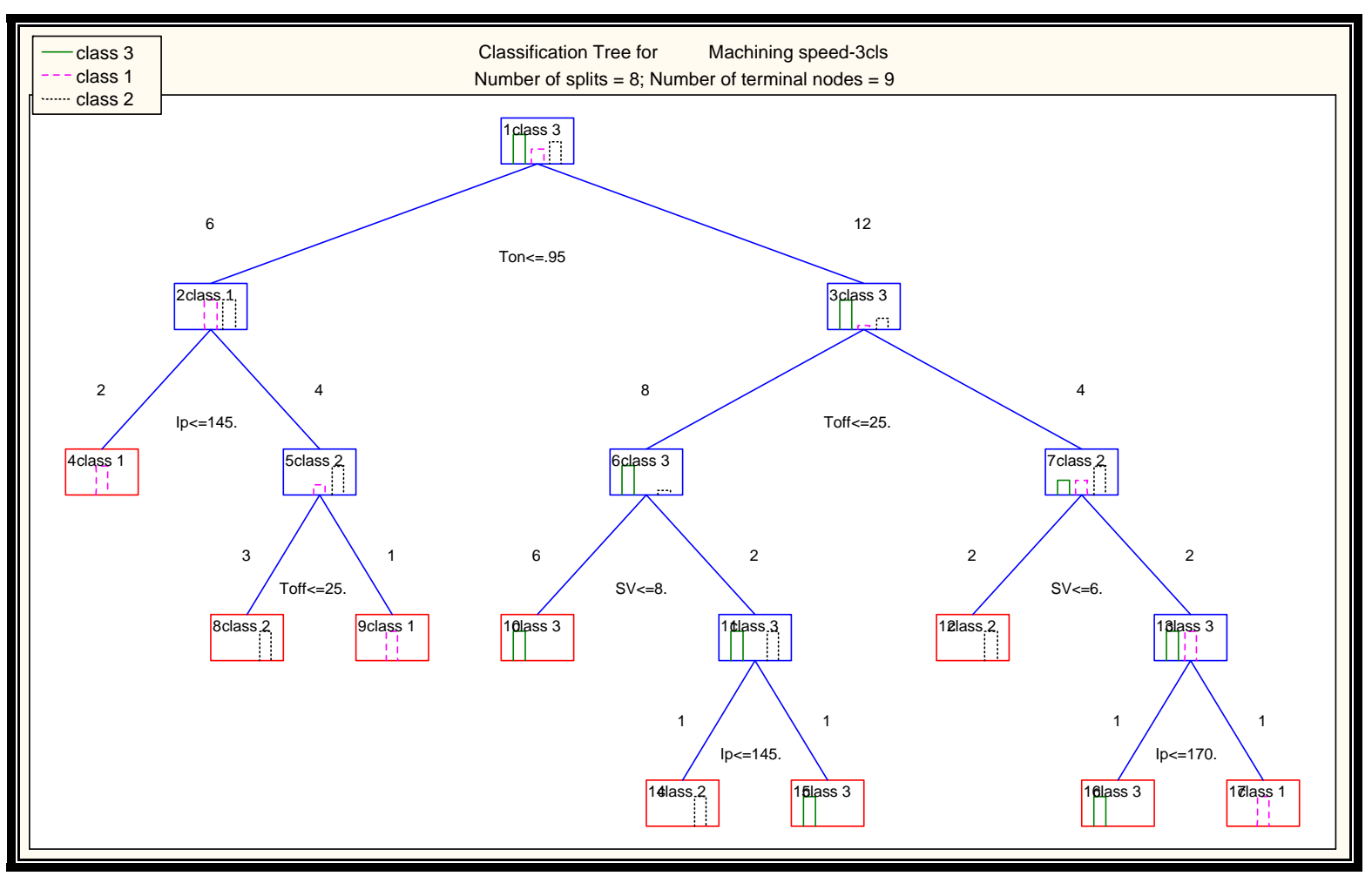

Fig. 8. Decision tree for machining speed (three classes)

Table 6

ANOVA results for machining speed

\begin{tabular}{cccccc}
\hline Effect & DF & SS & MS & F & \% contribution \\
\hline Pulse-on time & 2 & 2.47808 & 1.23904 & 19.76 & $52.64 \%$ \\
Pulse-off time & 2 & 1.06938 & 0.53469 & 8.53 & $21.42 \%$ \\
Peak current & 2 & 0.05151 & 0.02575 & 0.41 & $3.18 \%$ \\
Wire tension & 2 & 0.24671 & 0.12335 & 1.97 & $3.33 \%$ \\
Servo reference voltage & 2 & 0.11018 & 0.05509 & 0.88 & $19.43 \%$ \\
Dielectric flow rate & 3 & 0.30503 & 0.10167 & 1.62 & \\
Error & 4 & 0.25082 & 0.06270 & & \\
\hline Pooled error & 8 & 0.41251 & 0.05156 & & \\
\hline Total & 17 & 4.51171 & & & \\
\hline
\end{tabular}

Table 7

ANOVA results for Ra value in WEDM process

\begin{tabular}{cccccc}
\hline Effect & DF & SS & MS & F & \% contribution \\
\hline Pulse-on time & 2 & 0.92943 & 0.46472 & 145.68 & $91.65 \%$ \\
Pulse-off time & 2 & 0.01083 & 0.00542 & 1.70 & $1.07 \%$ \\
Peak current & 2 & 0.02043 & 0.01022 & 3.20 & $2.03 \%$ \\
Wire tension & 2 & 0.01563 & 0.00782 & 2.45 & $1.55 \%$ \\
Servo reference voltage & 2 & 0.00303 & 0.00152 & 0.47 & $1.61 \%$ \\
Dielectric flow rate & 3 & 0.01627 & 0.00542 & 1.70 & $2.09 \%$ \\
Error & 4 & 0.01276 & 0.00319 & & \\
\hline Pooled error & 6 & 0.015793 & 0.00263 & & \\
\hline Total & 17 & 1.008398 & & & \\
\hline
\end{tabular}


This observation is also validated in Fig. 9 where the predicator variable importance ranking of different control parameters for Ra response is exhibited. The role of pulse-on time in significantly affecting Ra values in WEDM process is also reassured from the AVOVA results of Table 7.

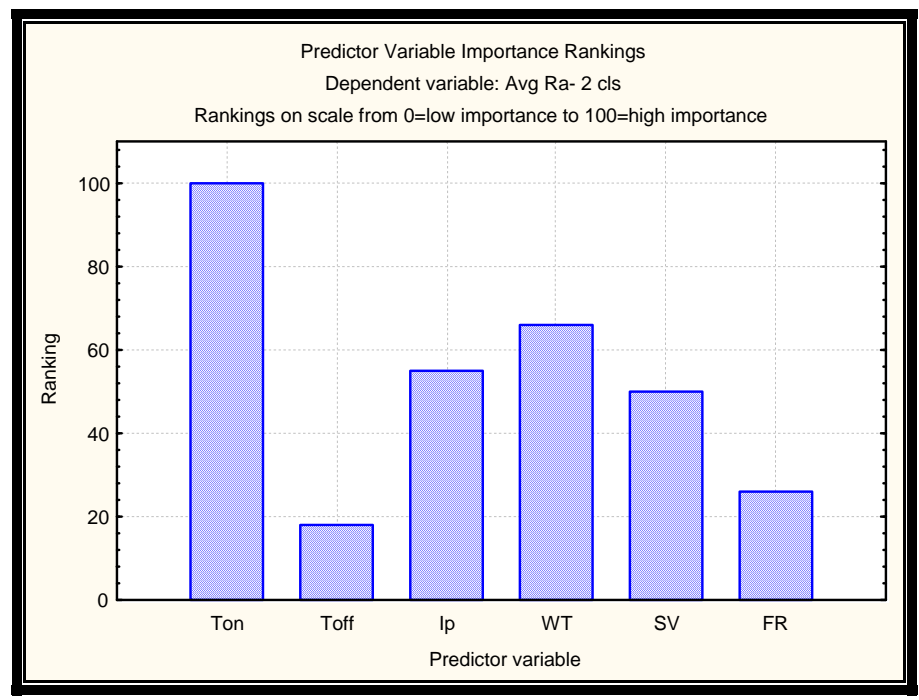

Fig. 9. Predictor variable importance ranking for Ra

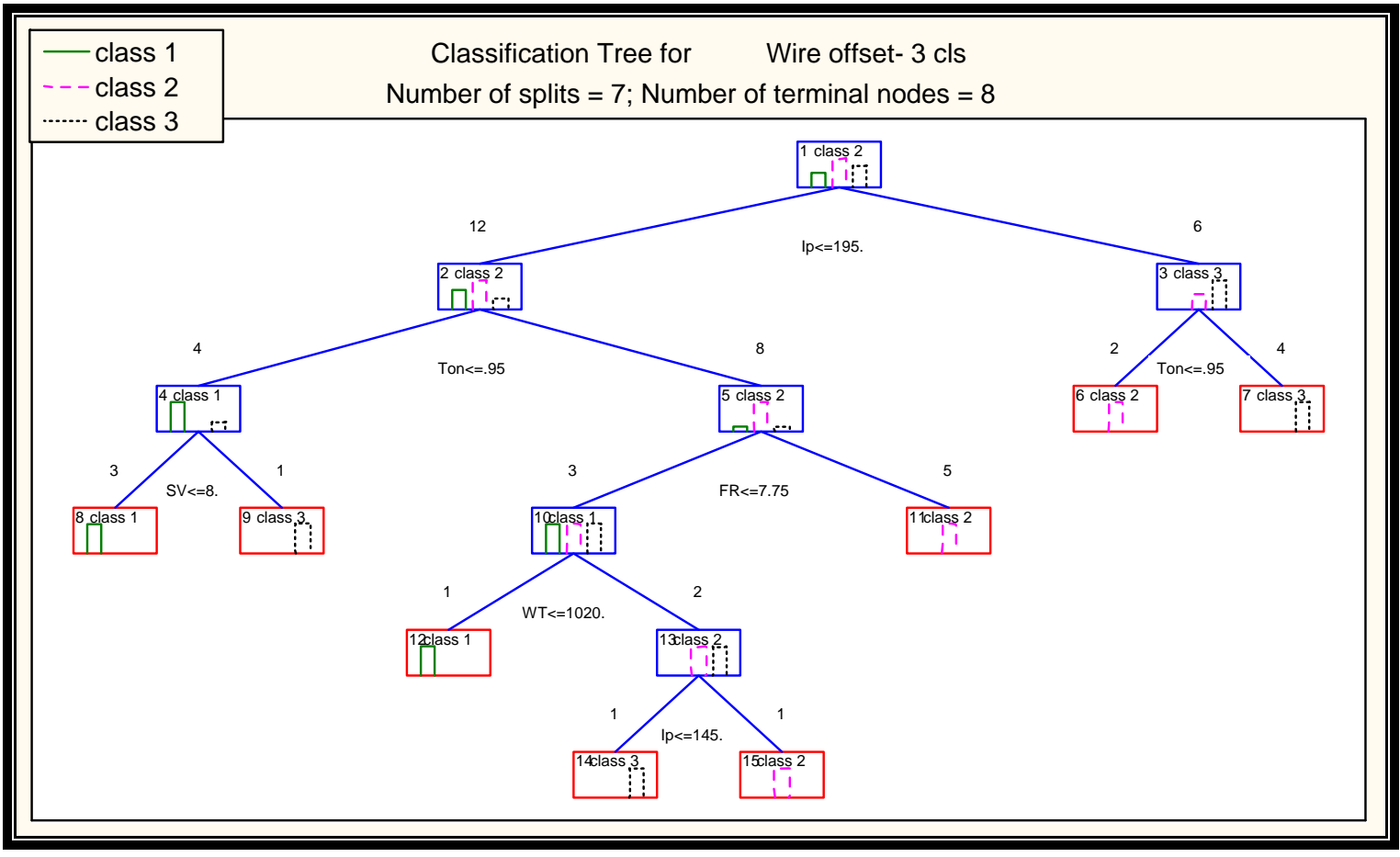

Fig. 10. Decision tree for wire offset (three classes)

Similarly, for wire offset response, using CART algorithm, the corresponding decision trees are developed. Fig. 10 shows the corresponding decision tree where the wire offset values are classified 
into three classes (Class 1: $0.14 \mathrm{~mm} \leq$ wire offset $<0.145 \mathrm{~mm}$, Class 2: $0.145 \mathrm{~mm} \leq$ wire offset $<0.150$ $\mathrm{mm}$ and Class 3: $0.150 \mathrm{~mm} \leq$ wire offset).

The predicator variable importance ranking of different WEDM process parameters for wire offset identifies pulse-on time, peak current and servo reference voltage as the main control parameters. Based on CART algorithm-based analyses, it is observed that for the considered WEDM process, pulseon time plays the major role in controlling the cutting speed and surface roughness values, while, pulseon time, peak current and servo reference voltage conjointly affect the wire offset response.

\subsection{Example 3: Laser beam machining process}

In laser beam machining (LBM) or more broadly laser material processing, machining is carried out utilizing the energy of coherent photons or laser beam, which is subsequently converted into thermal energy on interaction with most of the materials. Nowadays, laser is also finding applications in regenerative machining or rapid prototyping, like stereo-lithography, selective laser sintering etc. The material removal mechanism in LBM process is excellently detailed out (Dubey \& Yadava, 2008 2008 ; Parandoush \& Hossain, 2014). Dhupal et al. (2008) conducted 32 experiments to study the machining characteristics of pulsed Nd: YAG laser during micro-grooving operation on a workpiece of aluminum titanate. In that experimental plan, lamp current, pulse frequency, pulse width, assist air pressure and cutting speed of the laser beam were the machining process parameters, whereas, deviation of taper ( $\mathrm{D}_{\mathrm{T}}$ ) (in ${ }^{\circ}$ ) and deviation of depth $\left(\mathrm{D}_{\mathrm{d}}\right)$ (in $\mathrm{mm}$ ) were the considered responses. Each of the process parameters was set at five different levels. Now, in order to develop the corresponding decision trees, the response $\mathrm{D}_{\mathrm{T}}$ is classified into two and three classes.

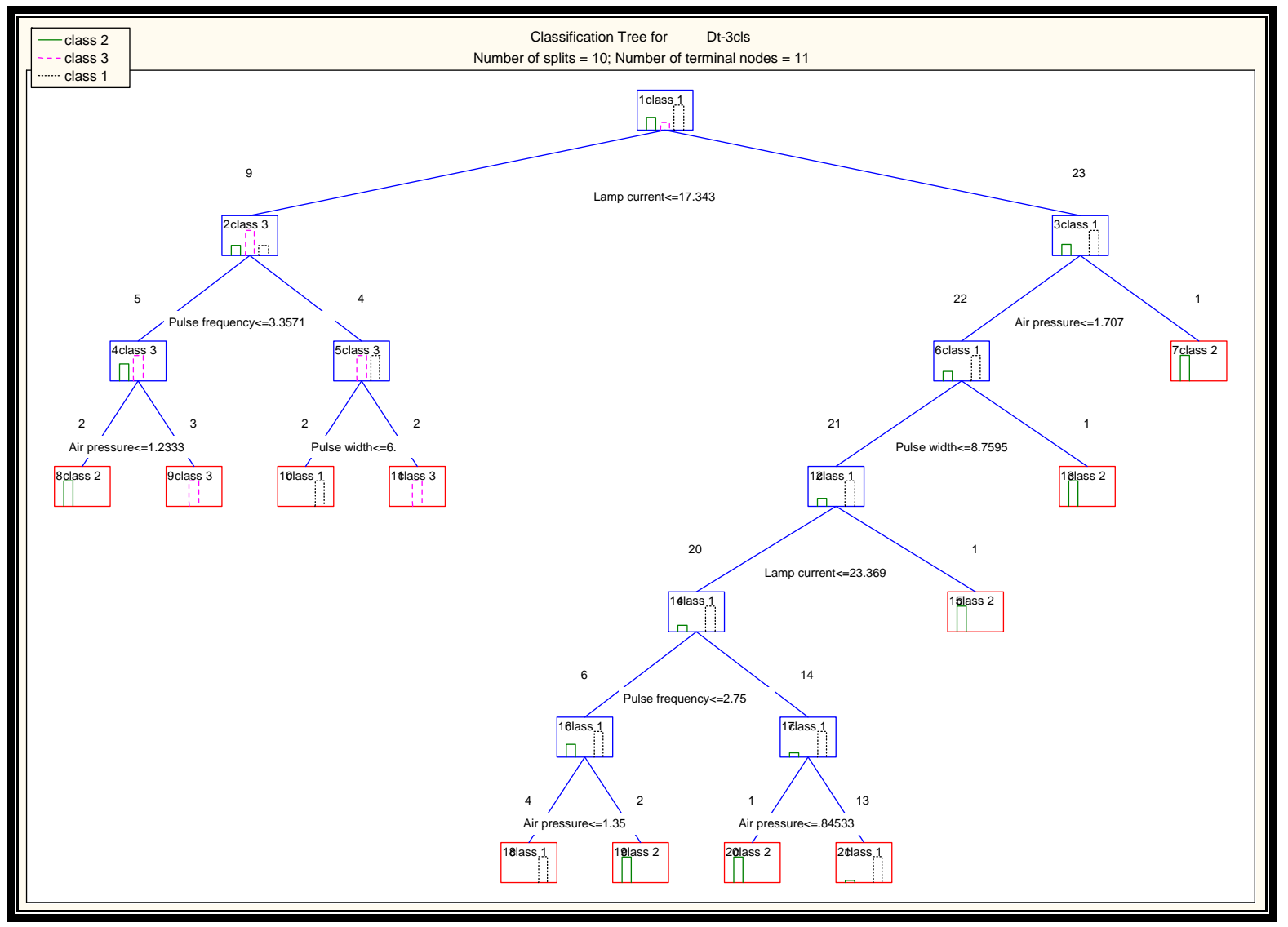

Fig. 11. Decision tree for deviation of taper (three classes) 
Fig. 11 exhibits the decision tree developed using CART algorithm for three class classification of $\mathrm{D}_{\mathrm{T}}$ (Class 1: $-1.14^{\circ} \leq \mathrm{D}_{\mathrm{T}}<4.323^{\circ}$, Class 2: $4.323^{\circ} \leq \mathrm{D}_{\mathrm{T}}<9.786^{\circ}$ and Class 3: $9.786^{\circ} \leq \mathrm{D}_{\mathrm{T}}$ ). From this tree, it is observed that four process parameters, i.e. lamp current, pulse frequency, pulse width and air pressure are mainly responsible for performing the split operations. Hence, these four parameters influence the response $\mathrm{D}_{\mathrm{T}}$, which can be reconfirmed from the predicator variable importance ranking of Fig.12 and ANOVA results of Table 8. In the decision tree of Fig. 11, only one dataset is misclassified.

For the other response $\mathrm{D}_{\mathrm{d}}$ of this laser beam machining process, based on CART algorithm, the corresponding decision tree of Fig. 13 is developed where the response $\mathrm{D}_{\mathrm{d}}$ is classified in three classes (Class 1: $-0.5165 \mathrm{~mm} \leq \mathrm{D}_{\mathrm{d}}<-0.260125 \mathrm{~mm}$, Class 2: $-0.260125 \mathrm{~mm} \leq \mathrm{D}_{\mathrm{d}}<-0.00375 \mathrm{~mm}$ and Class 3: $-0.00375 \mathrm{~mm} \leq \mathrm{D}_{\mathrm{d}}$ ). From this tree, it is observed that deviation of depth of the machined jobs is significantly affected by lamp current, pulse frequency, cutting speed and pulse width. Amongst these four process parameters, cutting speed has the maximum contribution in influencing the response $\mathrm{D}_{\mathrm{d}}$. These observations results are also validated in Fig. 14 where all the predictor variables are ranked in accordance of their relative importance. Dhupal et al. (2008) also investigated the same effects of the pulsed Nd:YAG laser machining process parameters on the responses as those obtained using the CART algorithm-based analyses.

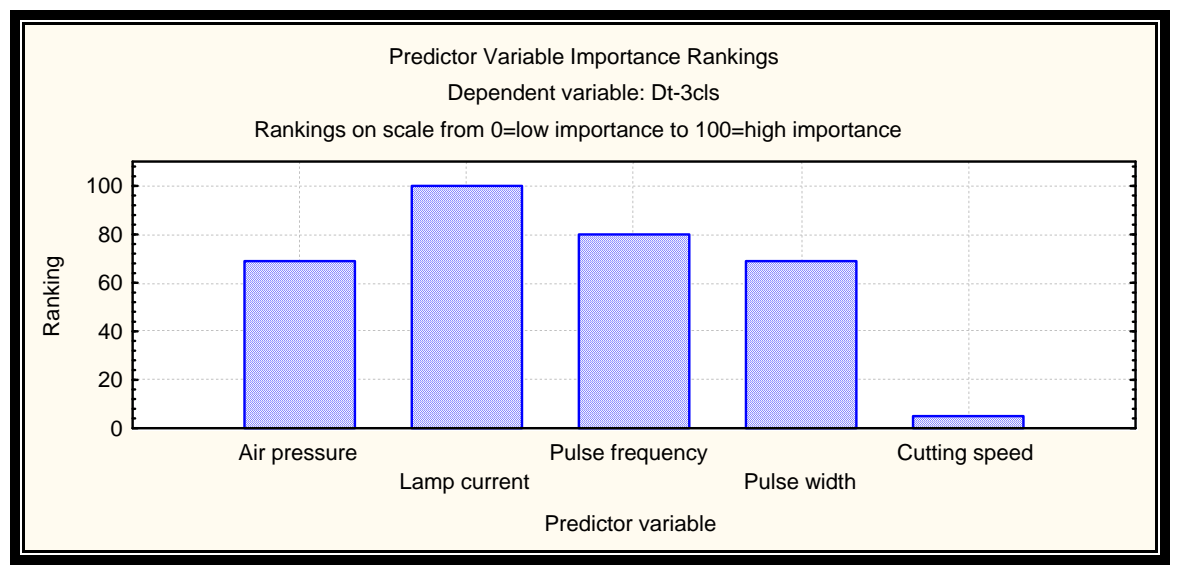

Fig. 12. Predictor variable importance ranking for deviation of taper

Table 8

ANOVA results for deviation of taper

\begin{tabular}{cccccc}
\hline Effect & DF & SS & MS & F & \% contribution \\
\hline Air pressure & 4 & 38.7497 & 9.687425 & 4.99 & $6.26 \%$ \\
Lamp current & 4 & 323.1082 & 80.77705 & 41.63 & $62.96 \%$ \\
Pulse frequency & 4 & 38.1108 & 9.5277 & 4.91 & $6.13 \%$ \\
Pulse width & 4 & 73.9539 & 18.48848 & 9.53 & $13.28 \%$ \\
Cutting speed & 4 & 6.2458 & 1.56145 & 0.80 & \\
Error & 11 & 21.3425 & 1.940227 & & $11.37 \%$ \\
\hline Pooled error & 15 & 27.5883 & 1.83922 & & \\
\hline Total & 31 & 501.5109 & & &
\end{tabular}




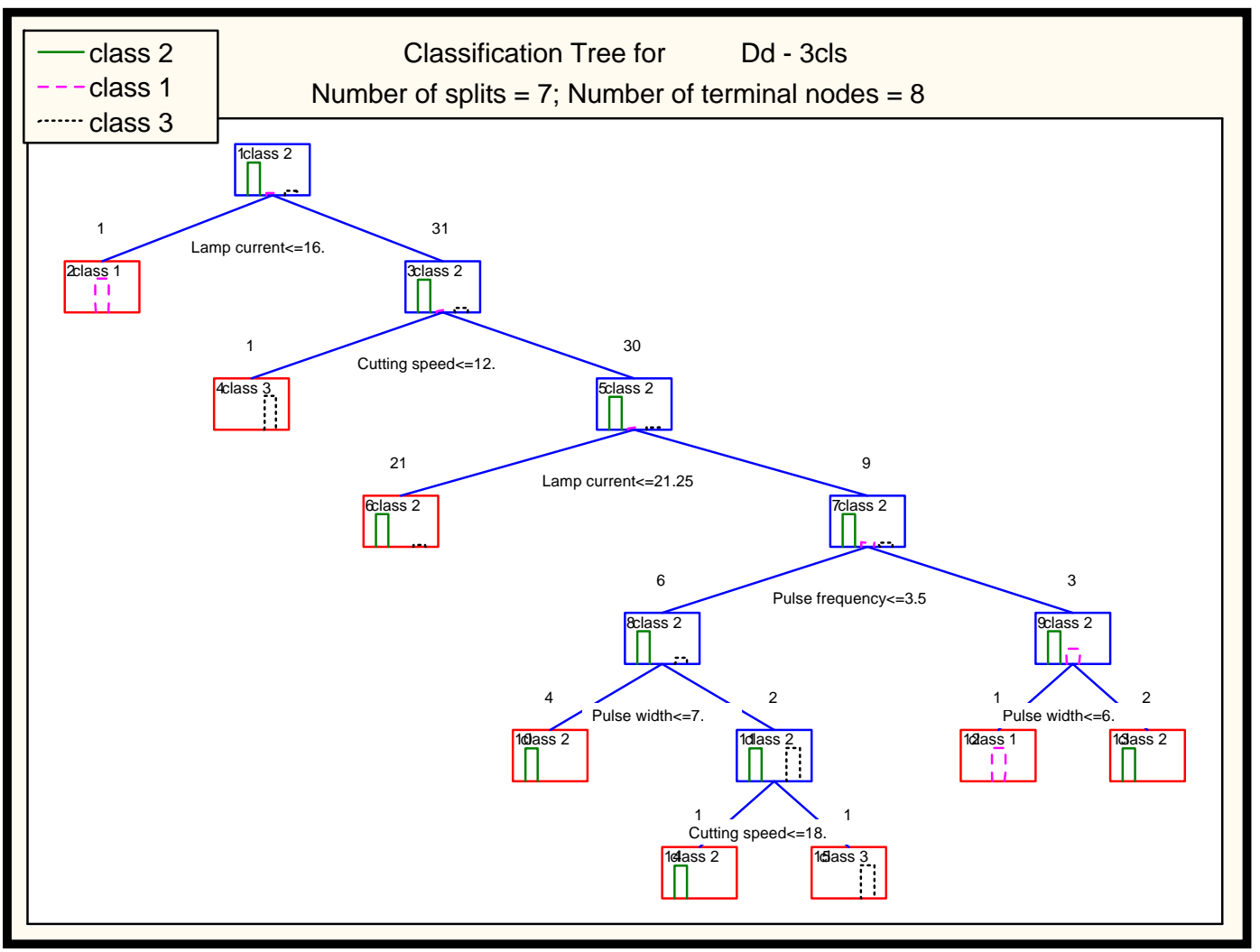

Fig. 13. Decision tree for deviation of depth (three classes)

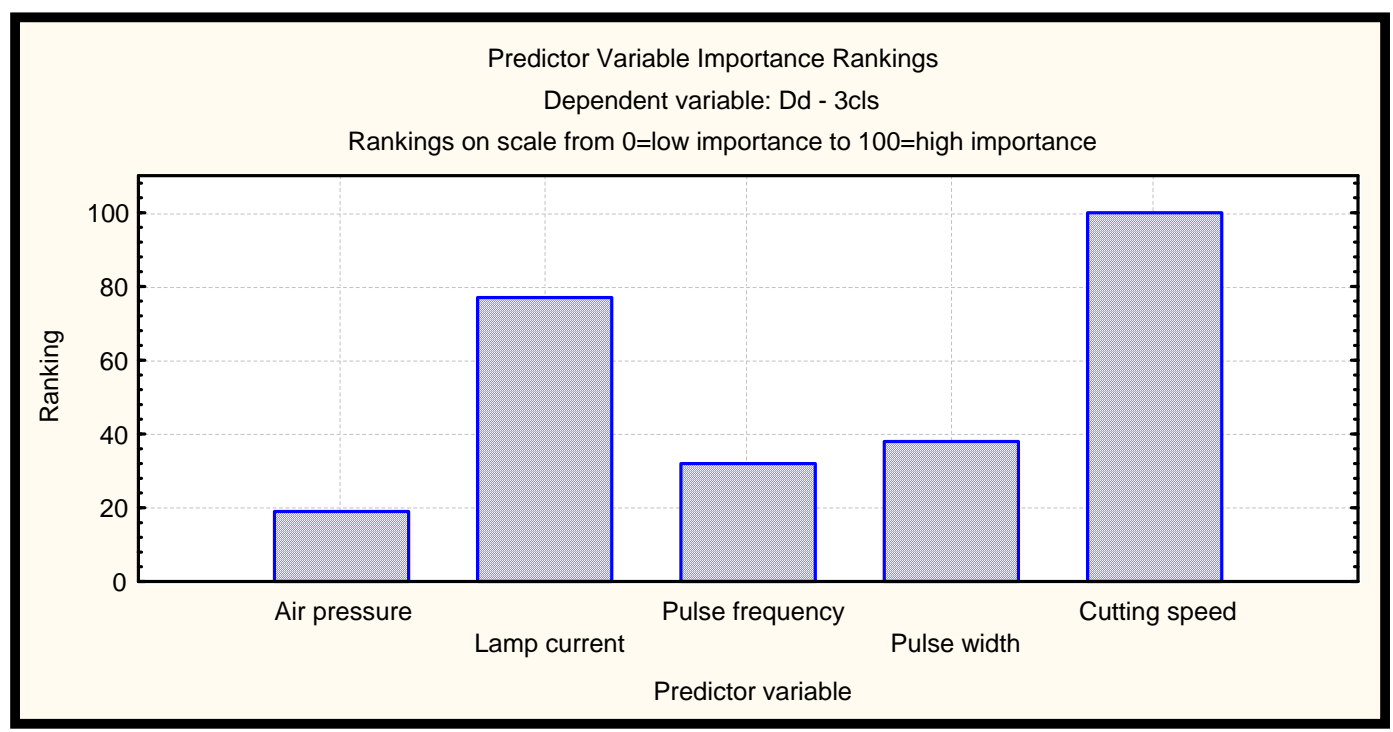

Fig. 14. Predictor variable importance ranking for deviation of depth 


\section{Conclusions}

In this paper, a data mining approach employing CART algorithm is applied to three NTM processes to identify the most important input parameters influencing the responses. It is observed that for micro electro discharge milling process, capacitance has the maximum contribution in controlling the surface roughness parameters, whereas, for TWR and MRR, feed rate is the most significant parameter. For WEDM process, pulse-on time is the most important parameter affecting cutting speed and surface roughness values, while, pulse-on time, peak current and servo reference voltage conjointly affect the wire offset response. In case of Nd:YAG laser machining process, for deviation of taper response, lamp current, pulse frequency, pulse width and air pressure are the main control parameters. On the other hand, for deviation of depth response, cutting speed is the most significant input parameter. All these observations are also validated using the ANOVA results. This data mining approach can also be applied to other machining processes to investigate the effects of different control parameters on the responses.

\section{References}

Breiman, L., Friedman, J.H., Olshen, R.A. \& Stone, C.J. (1984). Classification and Regression Trees. Monterey, CA: Wadsworth and Brooks.

Debroy, A. \& Chakraborty, S. (2013). Non-conventional optimization techniques in optimizing nontraditional machining processes: A review. Management Science Letters, 3, 23-38.

Dhupal, D., Doloi, B. \& Bhattacharyya, B. (2008). Parametric analysis and optimization of Nd:YAG laser micro-grooving of aluminum titanate $\left(\mathrm{Al}_{2} \mathrm{TiO}_{5}\right)$ ceramics. International Journal of Advanced Manufacturing Technology, 36, 883-893.

Dubey, A.K. \& Yadava, V. $\left(2008^{\mathrm{a}}\right)$. Laser beam machining - A review. International Journal of Machine Tools \& Manufacture, 48, 609-628.

Dubey, A.K. \& Yadava, V. $\left(2008^{b}\right)$. Experimental study of Nd:YAG laser beam machining - An overview. Journal of Materials Processing Technology, 195, 15-26.

Ho, K.H. \& Newman, S.T. (2003). State of the art electrical discharge machining (EDM). International Journal of Machine Tools \& Manufacture, 43, 1287-1300.

Ho, K.H., Newman, S.T., Rahimifard, S. \& Allen, R.D. (2004). State of the art in wire electrical discharge machining (WEDM). International Journal of Machine Tools \& Manufacture, 44, 12471259.

Kuriakose, S., Mohan, K. \& Shunmugam, M.S. (2003). Data mining applied to wire-EDM process. Journal of Materials Processing Technology, 142, 182-189.

Liu, Y.H., Li, X.P., Ji, R.J., Yu, L.L., Zhang, H.F. \& Li, Q.Y. (2008). Effect of technological parameter on the process performance for electric discharge milling of insulating $\mathrm{Al}_{2} \mathrm{O}_{3}$ ceramic. Journal of Materials Processing Technology, 208, 245-250.

Maimon, O. \& Rokach, L. (2005). Data Mining and Knowledge Discovery Handbook. New York: Springer.

Mehfuz, R. \& Ali, M.Y. (2009). Investigation of machining parameters for the multiple response optimization of micro electrodischarge milling. International Journal of Advanced Manufacturing Technology, 43, 264-275.

Parandoush, P. \& Hossain, A. (2014). A review of modeling and simulation of laser beam machining. International Journal of Machine Tools \& Manufacture, 85, 135-145.

Rajurkar, K.P., Sundaram, M.M. \& Malshe, A.P. (2013). Review of electrochemical and electrodischarge machining. Procedia CIRP, 6, 13-26.

Sarkar, S., Mitra, S. \& Bhattacharyya, B. (2005). Parametric optimization of wire electrical discharge machining of $\gamma$ titanium aluminide alloy through an artificial neural network model. International Journal of Advanced Manufacturing Technology, 27, 501-508.

Scott, D., Boyina, S. \& Rajurkar, K.P. (1991). Analysis and optimization of parameter combinations in wire electrical discharge machining. International Journal of Production Research, 29, 2189-2207. 
Skrabalak, G., Kozak, J. \& Zybura, M. (2013). Optimization of dry EDM milling process. Procedia CIRP, 6, $332-337$.

Spedding, T.A. \& Wang, Z.Q. (1997ª). Parametric optimization and surface characterization of wire electrical discharge machining process. Precision Engineering, 20, 5-15.

Spedding, T.A. \& Wang, Z.Q. (1997 $)$. Study on modeling of wire EDM process. Journal of Materials Processing Technology, 69, 18-28. 